\title{
O FLERTE EM SERVIÇOS ONLINE DE PAQUERA ${ }^{1}$
}

\author{
Flirting on online dating services
}

El coqueteo en servicios online de conquista

\begin{abstract}
Ricardo Fernandes
Doutorando vinculado ao Laboratório de Interações Mediadas por Computador (LIMC/UFRGS) e Bolsista Capes no Programa de Pós-Graduação em Comunicação da Universidade Federal do Rio Grande do Sul

fernandesricardo86@gmail.com
\end{abstract}

Alex Primo
Coordenador do Laboratório de Interação Mediadas por Computador (LIMC/UFRGS) e
Docente do Programa de Pós-Graduação em Comunicação
da Universidade Federal do Rio Grande do Sul
alex.primo@gmail.com

\section{Resumo}

O flerte se apresenta como importante estratégia para exprimir o desejo pelo outro. Este artigo reflete sobre como os diferentes agenciamentos e affordances dos serviços online de paquera transformam os relacionamentos na contemporaneidade. Após uma historicização das práticas amorosas e sexuais em diferentes tempos e culturas, este artigo discute os resultados de um questionário online que obteve 397 respostas. Conforme nossos achados, comprovou-se que Tinder é o aplicativo mais popular no segmento. Para além da busca por parceiros sexuais, identificou-se significativo uso desses serviços digitais para encontros românticos. Discute-se também as formas de apresentação de si e abordagem, a centralidade das imagens na interface desses sistemas, as conversações fluidas, a transição do flerte do ambiente online para o offline e a agência dos aplicativos.

Palavras-chave: Flerte. Serviços online de paquera. Práticas românticas e sexuais.

\begin{abstract}
Flirting presents itself as an important strategy to express the desire for the other. This article reflects on how the different agencies and affordances of online dating services transform relationships in contemporary times. After a historicization of love and sexual practices in different times and cultures, this article discusses the results of a questionnaire online, which obtained 397 responses. According to our findings, Tinder is the most popular application in the segment. In addition to the search for sexual partners, there was a significant use of these digital services for romantic encounters. This paper also discusses the ways of approaching and presenting oneself, the centrality of images on the interface of these systems, the fluid conversations, the transition from flirting online to offline environments and the agency of applications.
\end{abstract}

\footnotetext{
${ }^{1}$ O presente trabalho foi realizado com apoio da Coordenação de Aperfeiçoamento de Pessoal de Nível Superior - Brasil (CAPES) - Código de Financiamento 001.
} 
Key words: Flirt. Online flirting services. Romantic and sexual practices.

\section{Resumen}

El coqueteo se presenta como una estrategia importante para expresar el deseo por otra persona. Este artículo reflexiona sobre cómo los diferentes agenciamentos y affordances de los servicios de citas online transforman las relaciones en los tiempos contemporáneos. Después de una historización de las prácticas amorosas y sexuales en diferentes épocas y culturas, este artículo analiza los resultados de un cuestionario online, que obtuvo 397 respuestas. Según nuestros hallazgos, Tinder es la aplicación más popular en el segmento. Además de la búsqueda de parejas sexuales, hubo un uso significativo de estos servicios digitales para encuentros románticos. Este artículo también analiza las formas de presentarse y acercarse, la centralidad de las imágenes en la interfaz de estos sistemas, las conversaciones fluidas, la transición del coqueteo de los entornos online a los offline y la agencia de las aplicaciones.

Palabras clave: Coqueteo. Servicios de conquista online. Prácticas románticas y sexuales.

\section{INTRODUÇÃO}

As dinâmicas da corte e do desenvolvimento de relações sexuais e afetivas são hoje marcadas pelo atravessamento de affordances ${ }^{2}$ e agenciamentos dos serviços online de paquera. Com os recursos de geolocalização dos smartphones, os serviços online de paquera facilitam o encontro de pessoas que estão próximas, conforme distância máxima configurada no sistema. Aplicativos como Tinder, Happn e Grindr oferecem meios cada vez mais funcionais para facilitar futuros encontros offline. A criação de um perfil é o ponto de partida, no qual o usuário pode migrar informações previamente cedidas à outras mídias como Facebook ou Instagram. Nas plataformas Happn e Tinder, a cada pessoa visualizada na interface pode-se atribuir "coração" para exprimir interesse ou "X" para o desinteresse. A reciprocidade de corações permite que os usuários sejam notificados do "match" (Tinder) ou do "crush" (Happn) e a permissão para troca de mensagens, viabilizando que os sujeitos possam conversar.

Diferentemente das anteriores, Grindr oferece uma dinâmica diferente ao apresentar perfis de vários usuários conforme a proximidade. Voltada para gays, bi, trans e queer, o cadastro na mídia demanda apenas de um endereço de e-mail. O diálogo não está condicionado a aprovação anterior, uma vez que a plataforma permite enviar mensagens para

\footnotetext{
${ }^{2}$ Conforme conceituação de Gibson (1977) affordance remete à identificação das funcionalidades de um objeto a partir de seus atributos. As limitações oferecidas pelo objeto, consequentemente, condicionam a intervenção do agente humano. No caso da comunicação interpessoal não presencial por meio das plataformas de paquera refere-se a como os recursos expressivos e estéticos oferecidos por elas tanto facultam quanto limitam a atuação de seus usuários.
} 
qualquer perfil. Oferece ainda a possibilidade de acenar interesse a partir do envio de um “tap", a partir do qual a pessoa desejada é notificada ${ }^{3}$.

Com o atual aumento no consumo desses serviços, verificamos a apropriação dos recursos oferecidos por esses sistemas para o flerte, ou seja, para expressar a atração afetiva e/ou sexual pelo outro. Na contramão da hipótese de que os relacionamentos estão em crise na contemporaneidade (BONAVITTA, 2015; BAUMAN, 2004), este artigo busca explorar empiricamente a reconfiguração de práticas românticas e sexuais a partir do flerte em aplicativos de paquera. Para isso, propomos inicialmente uma reflexão sobre como a expressão do desejo pelo outro se deu em meio às transformações nos relacionamentos amorosos e sexuais na cultura ocidental. Na sequência, discutiremos o flerte e o modo como se dá em sua atual disposição nos serviços de paquera online. E, por fim, discutiremos os resultados de uma pesquisa empírica que conduzimos a partir de um questionário online respondido por 397 pessoas.

\section{AS TRANSFORMAÇÕES NOS RELACIONAMENTOS AFETIVOS E SEXUAIS}

Não se pode supor que a reciprocidade afetiva e a atração sexual sempre foram valorizados em relacionamentos na cultura ocidental. $\mathrm{O}$ apreço à racionalidade $\mathrm{e} \mathrm{o}$ autocontrole na Grécia antiga, por exemplo, inspirou a centralidade de questões econômicas no estabelecimento e manutenção de relações conjugais (LINS, 2012). Nutria-se uma espécie de dever social, uma missão na qual os cônjuges deveriam assumir para equilibrar as finanças das famílias envolvidas. Em função disso, quaisquer fatores que tirassem o grego de seu compromisso com a propriedade familiar (oikos), como a atração física e sexual, eram tidos como ameaças.

Entre os romanos, destacou-se uma perspectiva marcadamente controladora. Considerando o forte elo com o clã, agrupamento familiar regido pela descendência ancestral e a religião ${ }^{4}$, a união conjugal (VEYNE, 2009) herdou dos gregos o arranjo relacional por questões econômicas, incorporando esses valores ao processo. Na medida em que essa relação era incentivada pelo império (recompensas aos casais com maior número de filhos, por exemplo), as leis romanas acabavam por "coagir o mundo romano para o matrimônio" (ORTEGA, 2002, p.49). A punição aos adultérios, as relações extraconjugais, refletem esse

\footnotetext{
3 “Os taps podem ser usados para quebrar o gelo — você pode mostrar para outra pessoa que você está interessado sem ter que encontrar as palavras certas para iniciar uma conversa” (GRINDR, 2018).

${ }^{4}$ Veyne (2009, p. 189) informou que o paganismo greco-romano tratava-se de uma espécie de "religião à la carte", onde os indivíduos escolhiam qual ou quais divindades venerar.
} 
processo. Contrariar regras, costumes e ceder aos desejos foram ingredientes importantes para o reconhecimento do amor sexual apaixonado (LINS, 2012) como uma modalidade de relação afetiva irresistível. Para alguns, ter esse tipo de envolvimento representou um ato de rebelião contra uma cultura que impunha como ser, viver e sentir.

A queda do império romano e consequentemente da instância governamental em ditar como ser e viver no mundo, instalou uma configuração social dispersa, perdida e descrente. Elementos estes que favoreceram o crescimento da doutrina cristã. Com a centralidade do cristianismo, cultuou-se uma verdadeira ojeriza ao prazer sexual. Na visão dos cristãos, o despudor dos romanos foi a causa da destruição do império. Como medida para conter o ímpeto carnal, disseminou-se a prática do casamento "o mais cedo possível a fim de controlar, graças a uma vida conjugal lícita, as tensões explosivas da atração sexual" (BROWN, 2009, p. 239). A afetividade passa a ser construída sob as noções de pecado, fidelidade, conveniência familiar e outros nortes advindos da doutrina religiosa. A monogamia converte-se em um princípio basilar para a formação de um compromisso sólido, uma união que não deve ser dissolvida.

Na idade média, o amor cortês despontou como uma expressão amorosa que designa uma experiência que oscila entre o desejo sexual e a realização espiritual. Registrada em coletâneas biográficas e nos poemas e romances corteses (BARROS, 2015) ${ }^{5}$ a expressão do interesse sexual e afetivo ganha novas tonalidades. As trocas de gentilezas, gracejos e cortesias como demonstrações que exprimiam a atração física foram largamente propagandeada pelos trovadores (BARROS, 2015). Não é à toa que o verbo "trovar" passou também a designar o ato fundado em cortejar, conquistar o outro.

Grande parte do repertório das demonstrações de desejo do amor cortês foi incorporado pelo ideal do amor romântico que emergia desde o final do século XVIII. Graças ao advento do ideal romântico, amor e liberdade puderam ser vistos como algo desejável (GIDDENS, 1993). Introduziu-se a ideia de uma história comum na qual os sujeitos convertem a busca pelo parceiro em uma verdadeira odisseia "em que a auto-identidade espera sua validação a partir da descoberta do outro” (p.57). Na visão de Giddens o amor romântico exigiu um questionamento contínuo sobre como cada um se sente perante o outro. Dos

\footnotetext{
${ }^{5}$ Barros (2011) acreditou que boas partes dessas vivências se davam na clandestinidade de relações adúlteras. "É o caso, por exemplo, da 'vida' de Guilhem de Capestanh. Conta-se que o trovador era enamorado da esposa de um poderoso senhor feudal, que lhe correspondia a afeição permitindo que ele a louvasse através de suas canções. Tornado consciente da vassalagem clandestina por alguns aduladores e maledicentes, o Barão mandou que assassinassem o trovador e extraiu-lhe o coração".
} 
cristãos, herdou-se o ideal de uma relação pautada "até que a morte nos separe", associada a formação de família e à maternidade. No interior do alinhamento burguês-cristão, acabou-se por enfatizar a constituição familiar, sustentando a prática de um tipo de relação que padronizou os papéis do homem e da mulher. O primeiro deveria prover o sustento familiar e a segunda dedicar-se aos afazeres domésticos e criação dos filhos.

Na modernidade, a chegada dos meios de transportes e o processo de urbanização das cidades criaram condições para a prática do flerte longe da vigília da família e da escola. No Brasil, o footing, hábito trazido da Europa de passear calmamente por ruas e praças, facilitou o encontro dos jovens em espaços públicos. "'Fazendo o footing', as moças se ofereciam ao flirt e podiam de algum modo [...] escolher seus pares ou, ao menos, selecioná-los entre os que procuravam atraí-las." (AZEVEDO, 1978, p. 120). O flerte visava a conquista amorosa e constituía o primeiro passo para o namoro. O autor (1978) ainda observou que, mais do que a troca de olhares e galanteios, o flerte passava a incluir o tocar e o pegar.

Ainda no século XIX, fazia parte do flerte a moça preparar uma refeição em sua casa para seu pretendente, acompanhada pelo olhar atento de seus pais. Com a chegada do século $\mathrm{XX}$, o homem passa a convidar a moça para jantar fora. Cabia a ele pagar todas as despesas. No primeiro caso, o convite para o almoço ou janta era feito pela moça e sua família. No segundo caso, é o homem que faz o convite. Mesmo assim, Whitty (2003) defende que a iniciativa no flerte costumava partir da mulher, pois é ela que deixava transparecer interesse, a partir de pistas não verbais (olhares e trejeitos). A descrição de Azevedo (1978) também mostra uma postura ativa das moças durante o flerte. Por outro lado, não se pode ignorar que em uma era machista é o homem que deveria conduzir os movimentos iniciais, como o primeiro beijo, pedir a mão da moça em casamento, etc.

As amarras que prendiam as práticas afetivas começam a se romper com a indústria cultural, a luta dos homossexuais em expressar seus sentimentos publicamente e a emancipação feminina que, somadas às transformações econômicas e políticas, alimentam a chamada revolução sexual em meados do século XX. Em resposta a uma criação conservadora, a batida pesada do rock'n'roll, as mensagens de paz, amor e sexo livre embalam o ar de rebeldia de jovens e adultos nas décadas de 1960 e 1970. Para Del Priore (2006), os produtos da indústria fonográfica e audiovisual da época (inclusive a pornografia) tiveram participação fundamental na reivindicação por maior liberdade sexual. Com o fortalecimento do protestantismo em países exportadores de produtos culturais, como Estados Unidos e Inglaterra, a valorização extrema da virgindade perde sua força. A mulher pode transitar sem a 
vigília familiar de outros tempos, podendo inclusive manifestar interesse afetivo e sexual sem sofrer tantos julgamentos. Ao redor das músicas e filmes, emergem os festivais, concertos, cinemas e boates noturnas como espaços modernos para o encontro afetivo de homens e mulheres. Com a flexibilização da moral, a sexualidade torna-se mais fluida.

\subsection{O Flerte e a Paquera}

O flerte compreende um evento comunicativo de elementos linguísticos e paralinguísticos $^{6}$ (CAMERON AND KULICK, 2006) voltado para exprimir desejo pelo outro. A prática pode se dar tanto a partir de uma relação casual quanto de uma relação prévia (até mesmo uma amizade) no qual uma das partes deseja maior aproximação e consumação (WHITTY, 2003; HALL ET AL., 2015; HENNINGSEN ET AL., 2008). O flerte se caracteriza por ser ocasional (MILLER, 2003), envolver provocações afetivas (WHITTY, 2003), insinuações (MORTENSEN, 2017), e por ter uma ambiguidade particular (HENNINGSEN ET AL.,2008) que resulta em uma imprecisão (MORTENSEN, 2017; WHITTY, 2003) do que é expressado. Essas características oferecem um campo de possibilidades produtivas e interpretativas da expressão do interesse romântico e/ou sexual de maneira estratégica. Seja pelo receio da rejeição, dos olhares dos familiares ou dos outros em espaços públicos, o flerte nasce como uma forma de comunicação que camufla o sentido do que se deseja expressar.

Independente da motivação ${ }^{7}$, a adoção de recursos paralinguísticos possuem papel fundamental na dinâmica do flerte. Condutas como jogar os cabelos para o lado, morder os lábios ou erguer a sobrancelha são formas não verbais de expressar o desejo pelo outro. Em substituição à essas expressões e gestos comuns nas interações offline, Whitty (2003) apontou o uso dos

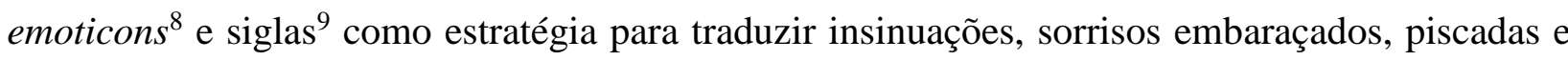
beijos em interações via e-mail, salas de bate papo e sites de namoro. A publicação de imagens em sites e aplicativos de paquera, recursos de áudio e vídeo, avatares em realidade virtual (como no Second Life) e até os emojis (incorporados nos teclados de smartphones e tablets) contribuem para a presença do corpo nas dinâmicas de flerte na rede.

\footnotetext{
${ }^{6}$ Como pistas não verbais (um olhar, um gesto, etc.).

${ }^{7}$ Henningsen et al (2008) apontaram outras motivações para a prática do flerte, tais como buscar diversão, alimentar a autoestima ou persuadir o endereçado a fazer algo pelo remetente. Em cada uma delas, a natureza do flerte se diferencia. No trabalho, por exemplo, a imprecisão pode causar constrangimentos, ressentimentos ou ser vista como assédio sexual.

${ }^{8}$ Fusão das palavras inglesas "emotion" e "icon", emoticon é um recurso paralinguístico empregado para exprimir reações e sentimentos em mensageiros online.

9 Whitty (2003) cita a sigla "LOL" (laughing out loud) e "BG" (big grin). Na internet, o primeiro refere-se a risos altos e o segundo a um sorriso largo.
} 
Outra prática que merece aqui atenção é a paquera. Com as conquistas da mulher, do enfraquecimento das normas familiares e religiosas e como os jovens vieram a passar cada vez mais tempo longe de casa, Azevedo (1978) descreve a popularização da paquera, um relacionamento mais impaciente e menos estruturado. Se o flerte era tido como o passo inicial para o advento de um namoro, que mais tarde desembocaria no casamento, na paquera é mais frouxo, despretensioso. Nas últimas décadas, a paquera entre os jovens tornou-se cada vez mais voltada para o prazer e para experimentações afetivas e sexuais. Sua duração também passou a apresentar grande variabilidade, podendo durar apenas algumas horas, como na prática do "ficar".

\subsection{A Reconfiguração do flerte e do amor na contemporaneidade}

Como vimos, as transformações culturais na afetividade e sexualidade reconfiguraram a maneira como nos envolvemos afetivamente. Na visão de Castro (2014) o ponto da virada encontra-se no momento em que estar junto deixa de ser um caminho para o casamento. Ainda que concordem que é a solidez do compromisso que define o amor romântico, Giddens (1993) e Bauman (2004) chegam a conclusões distintas sobre a crise do "até que a morte os separe". Enquanto o primeiro observou a desvinculação entre a sexualidade e o casamento, o advento de tecnologias contraceptivas e meios de reprodução sem atividade sexual, e a reivindicação do prazer por parte da mulher como sintomas da emergência de uma "sexualidade plástica" e consequentemente de uma nova maneira de se relacionar, o segundo atentou à fluidez que essas modalidades relacionais tomaram.

Para Giddens (1993), a sexualidade plástica admitiu que o sexo pudesse ser tido como como uma atividade voltada para a satisfação individual, desvinculada de uma finalidade reprodutiva. Além dela, as uniões homossexuais e a alta incidência de divórcios abriram caminho para o surgimento do "amor confluente" (GIDDENS, 1993), uma "relação pura", na qual os vínculos afetivos e sexuais se tornam mais contingentes. A pureza sexual e idealização projetiva de outrora cedem espaço para uma relação na qual os envolvidos permanecem juntos enquanto obtiveram satisfações individuais, transformando "a realização do prazer sexual recíproco em um elemento chave na manutenção ou dissolução do relacionamento" (GIDDENS, 1993, p.73). Ao ver esse mesmo movimento, Bauman (2004) entendeu que a fragmentação dos vínculos produzidos pelo amor romântico se fragilizou em função do rompimento com toda uma organização social pautada na solidez de instituições, padrões e regras. Inseridos em uma configuração de incertezas e inconstâncias, a fluidez do 
que chama de modernidade líquida — onde tudo transforma-se o tempo todo - , direcionou a valorização da conexão.

No entendimento do autor (2004) relacionar é tido como um compromisso sólido, longevo, enquanto conectar prescreve uma relação efêmera. Esta distinção o faz defender o amor líquido (fluido e inconstante) como uma tendência contemporânea. O senso de urgência atual endereça o desenvolvimento de relações pautadas no prazer instantâneo. Consequentemente, investir a longo prazo, cultivar o desejo na busca da durabilidade do sentimento afetivo, converteu-se em algo irritante e insustentável. Em um mundo que preza pela aceleração, retardar a satisfação tornou-se o pior dos sacrifícios. E, nesse sentido, ceder aos impulsos reflete uma predisposição para o desenvolvimento de prazeres passageiros, fadados à autodestruição assim que a posse se completa. No que toca as parcerias sexuais, Bauman (2004) apontou que se deixa em aberto as possibilidades românticas, na esperança de que possam ser melhores que as anteriores.

Na esteira da análise de Bauman (2004) sobre o estímulo da internet em promover novas formas de encontros sociais, Bonavitta (2015) buscou refletir sobre a participação das redes digitais nas transformações da experiência afetiva e sexual. No momento em que os serviços de comunicação online se estabelecem como espaços próprios da modernidade líquida, os serviços online de paquera emergem como uma espécie de "delivery sexualamoroso", no qual as emoções ocupam segundo plano. Com isso, os sujeitos acabam "[...] abandonando cada vez mais as noções de 'conquista', 'paquera' e 'romance'” (BONAVITTA, 2015, p.202 $)^{10}$. Endossando, portanto, as críticas levantadas por Bauman (2004) de que não há mais espaço para o amor romântico na realidade atual.

Ainda que reconheçamos as dificuldades e transmutações da experiência românticoamorosa e sexual na contemporaneidade, seria irresponsável sustentar sua extinção em função do uso intenso de tecnologias digitais (FERNANDES, 2018). Os argumentos apontados certamente provocam o debate sobre a questão em nosso tempo, mas pecam pela excessiva comparação com os relacionamentos característicos de outras épocas, lançando um olhar saudosista.

Considerando as interpretações sobre as transformações nas relações afetivas e sexuais expostas até aqui, cabe agora questionarmos qual o impacto dos chamados aplicativos de paquera na prática do flerte a partir da condução de um estudo empírico.

\footnotetext{
${ }^{10}$ No original: "[...]abandonando cada vez más las nociones de 'conquista', 'coqueteo' y 'romance'."
} 


\section{PROCEDIMENTOS METODOLÓGICOS E RESULTADOS}

A investigação que conduzimos sobre as práticas afetivas nos chamados aplicativos de paquera se apoiou em questionários semiabertos via Google Forms. Organizadas em 3 seções (aplicativos de paquera, paquera online e identificação), o questionário contou com 26 perguntas: 20 de múltipla escolha (11 com opções fechadas e 9 com a opção de sugerir outras informações não contempladas pelas alternativas oferecidas), 1 caixa de seleção em que o respondente deveria escolher opções dentre uma lista pré-definida (ou poderia sugerir outras alternativas) e 5 questões abertas.

A divulgação do questionário se ancorou em duas estratégias. A primeira centrou-se na propagação do link do questionário nos perfis pessoais dos pesquisadores e em grupos de discussões do Facebook ${ }^{11}$. A segunda deu-se pela repercussão de matéria sobre o estudo na Revista Veja (no site ${ }^{12}$ e em sua página no Facebook ${ }^{13}$ ). Disponível entre os meses de fevereiro e junho de 2018, o questionário obteve um total de 807 respostas. Os dados foram tabulados manualmente com auxílio da plataforma Excel e as questões abertas, ou com alternativas incluídas pelos respondentes, foram agrupadas conforme análise de conteúdo temática (BARDIN, 2004) ${ }^{14}$.

Considerando a quantidade de respostas das regiões Sul e Sudeste (FIG.2) e das três primeiras opções de faixa etária no questionário, focamos a análise nas respostas dos sujeitos dessas regiões e com idade entre 21-38 anos ${ }^{15}$. Neste recorte, $68 \%$ dos entrevistados informaram ser do sexo biológico feminino e $32 \%$ do sexo biológico masculino. Em termos de escolaridade, $74 \%$ informam estar cursando ou já tem uma pós-graduação, $24 \%$ estão fazendo ou têm uma graduação completa, $2 \%$ estão cursando ou têm o ensino médio. Já a orientação sexual, $67 \%$ se definem heterossexuais, $18 \%$ homossexuais, $14 \%$ bissexuais, $1 \%$ diz ser panssexual (FIG. 1) ${ }^{16}$.

\footnotetext{
${ }^{11}$ Grupos como Amizade, Namoro e Amor disponível em: https://www.facebook.com/groups/153330265340591/; Paquera online: Amor sem fronteiras. Disponível em: https://www.facebook.com/groups/668690356608272/.

12 Matéria disponível em: https://abr.ai/2NhgFfR

${ }^{13}$ Postagem disponível em: https://bit.ly/2MU3yEv.

${ }^{14}$ Nas informações coletadas na seção sobre os aplicativos e paquera online, consideramos como válidas apenas as respostas daqueles que informaram utilizar serviços online de paquera.

${ }^{15}$ As faixas etárias entre 21-26 anos, 27-32 anos e 33-38 anos juntas somam 90\% do total de respostas coletadas.

${ }^{16}$ Vale apontar que alguns gráficos que serão aqui mostrados apresentam variações nos números de respostas válidas em função do questionário não obrigar os entrevistados a responderem todas as questões, com exceção da seção de identificação. Nela, mesmo sendo obrigatória, havia questão que permitia a inclusão de respostas para além das opções apresentadas.
} 
Figura 1- Dados Demográficos ${ }^{17}$
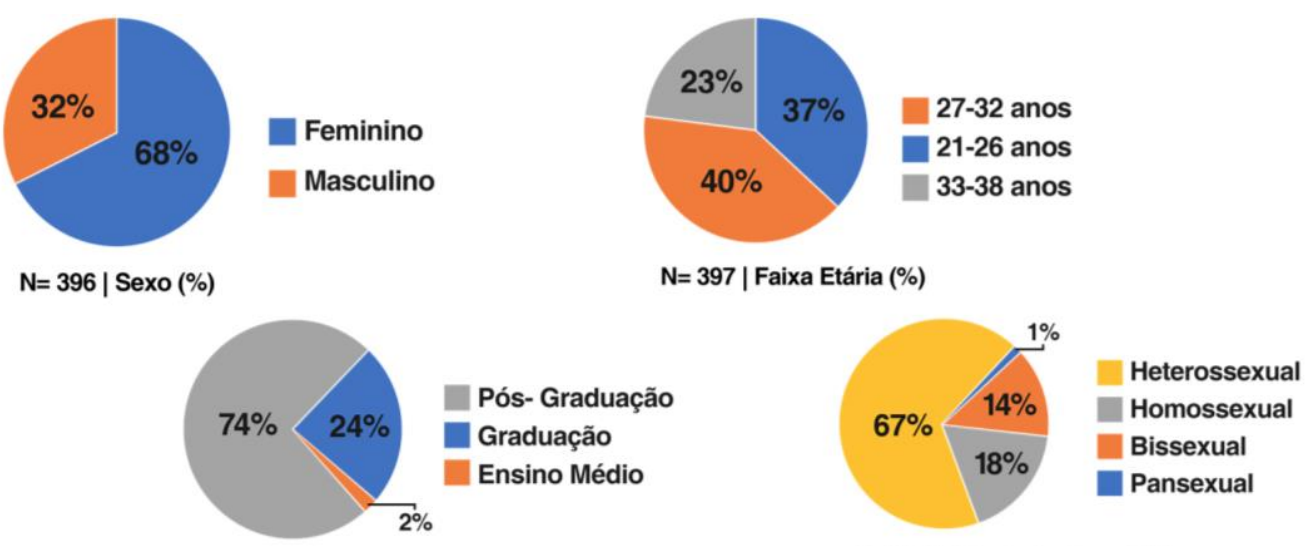

$\mathrm{N}=397$ | Escolaridade (\%)

$\mathrm{N}=397$ | Orientação Sexual (\%)

Fonte: Elaborado pelos autores.

A segunda seção do questionário buscou compreender a maneira como os respondentes encaram as plataformas de paquera e como estas se articulam às suas demandas afetivas e sexuais. A maioria dos respondentes (77\%) informou que utiliza plataformas de paquera. Destes, 70\% afirmam que suas motivações afetivas e sexuais direcionam a escolha das plataformas de paquera informadas. Dentre as opções de motivações, $40 \%$ revelou utilizar apps de paquera para todas as motivações disponíveis: conhecer pessoas para relações sexuais, para amizades e para namoro. É interessante observar que a opção de "conhecer pessoas para namoro" obteve 30\% das respostas, e apenas "sexo", 20\% (FIG.2). Este resultado vai contra o estigma de que tais aplicativos são utilizados basicamente para a busca rápida de parceiros sexuais.

\footnotetext{
17 O número de respostas válidas oscila em função da liberdade que demos ao respondente em assinalar as opções ou pular a questão. No caso da alternativa sobre sexo, por exemplo, um respondente optou por informar que identidade de gênero seria uma questão mais adequada, optando por não responder.
} 
Figura 2 - Estados e seção aplicativos ${ }^{18}$

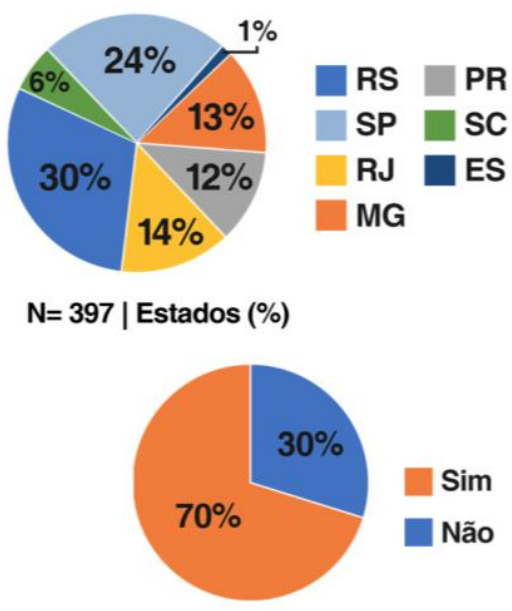

$\mathrm{N}=305$ | Sua motivação direciona a plataforma? (\%)

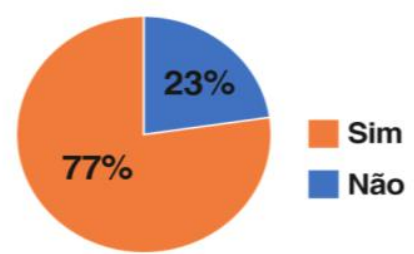

$\mathrm{N}=397$ | Você utiliza plataforma de paquera? $(\%)$

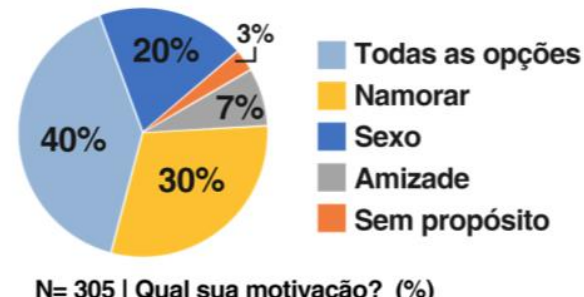

$\mathrm{N}=305$ Qual sua motivação? (\%)

Fonte: Elaborado pelos autores.

Quanto às plataformas utilizadas, os respondentes podiam assinalar entre as opções de serviços apresentadas ${ }^{19}$ e/ou inserir outros. O agrupamento de respostas mais expressivo destacou o Tinder e um segundo serviço de paquera diferente $(42 \%)^{20}$. Em segundo, o uso individual da plataforma Tinder (31\%). Em terceiro, a plataforma Happn foi mencionada individualmente (11\%). O uso do Tinder e mais outros 2 serviços diferentes (10\%) e do Tinder com outros 3 serviços diferentes (5\%), respectivamente em quarto e quinto. Por último, o uso do Happn com uma segunda plataforma diferente (1\%). Desse modo, observou-se a tendência de utilizar simultaneamente diferentes serviços de paquera ${ }^{21}$. Dentre os motivos apontados pelos respondentes que assinalaram "não utilizar plataformas de paquera"22 (podendo ter utilizado no passado), $57 \%$ informou já ter um parceiro(a), namoro, casamento, $34 \%$ revelou desinteresse ou incompatibilidade com a dinâmica dos serviços, $2 \%$ indisponibilidade técnica

\footnotetext{
18 A variação no número de respostas válidas nos gráficos das perguntas sobre se a motivação direciona a escolha da plataforma, qual a motivação da escolha e a plataforma que está utilizando se justificam em função de considerarmos apenas as respostas daqueles que responderam utilizar plataformas de paquera $(77 \%)$ e da vontade do entrevistado em responder as questões, já que não eram obrigatórias.

${ }^{19}$ A lista de plataformas foi pautada pela quantidade de downloads feitos na loja virtual do Google Play, a qual informa os aplicativos mais populares do segmento.

${ }^{20}$ Categorização criadas a partir da frequência de menções dos respondentes. Nelas, Tinder sempre era o primeiro associado à uma segunda, terceira, quarta ou mais plataformas de paquera.

${ }^{21}$ Além das 10 plataformas colocadas como opções no questionário, os respondentes relataram outras 20, tais como Scruff, Hornet, Adote um cara, Bumble, Pof, Growlr, Lovoo, Jaumo, Brenda, Date in asia, Meef, 'F*ck, Marry, Kill', Dating.com, Woof, Tastebuds, Her, Wapa, Yellow e Ashley Madison.

${ }^{22}$ Pergunta destinada para os $23 \%$ que informaram não utilizar plataformas de paquera, conforme mostra o gráfico na Figura 2.
} 
ou de acesso. Vale destacar ainda que $7 \%$ dos respondentes analisados não apresentaram justificativas $^{23}$ (FIG. 3).

Figura 3 - Uso dos aplicativos ${ }^{24}$.

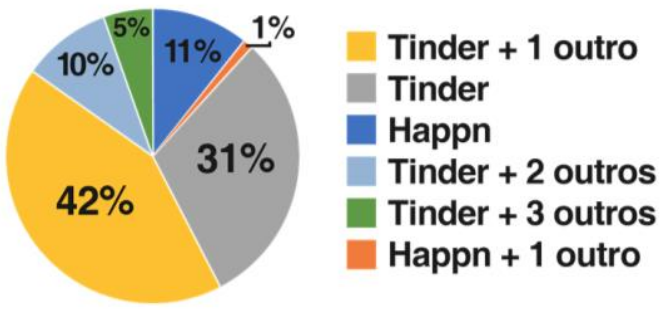

$\mathrm{N}=283$ | Qual plataforma de paquera está usando? (\%)

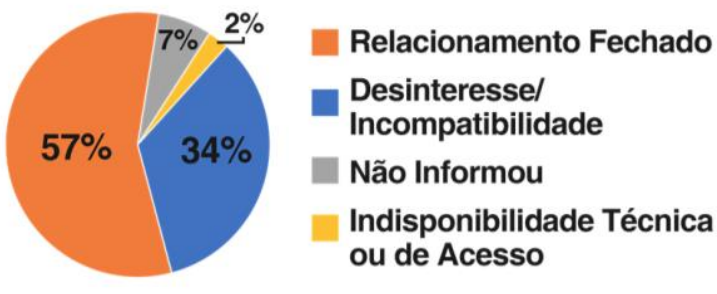

$\mathrm{N}=\mathbf{8 8}$ | Por qual motivo não utilizar plataformas de paquera? (\%)

Fonte: Elaborado pelos autores.

$\mathrm{Na}$ terceira seção do questionário buscamos coletar como os respondentes avaliam os perfis e flertam a partir dos serviços de paquera. Observou-se que dentre as informações apresentadas nos perfis dos serviços de paquera, 34\% revelam focar nas preferências e gostos informados $^{25}, 30 \%$ na seleção de fotos, e $28 \%$ em atentar em características físicas. Já em seus próprios perfis, $45 \%$ consideram que as suas fotos chamam mais atenção, $31 \%$ afirmaram ser as informações sobre suas características físicas, e $22 \%$ as preferências e gostos informados (FIG. 4).

Figura 4 - Percepção dos perfis nos aplicativos

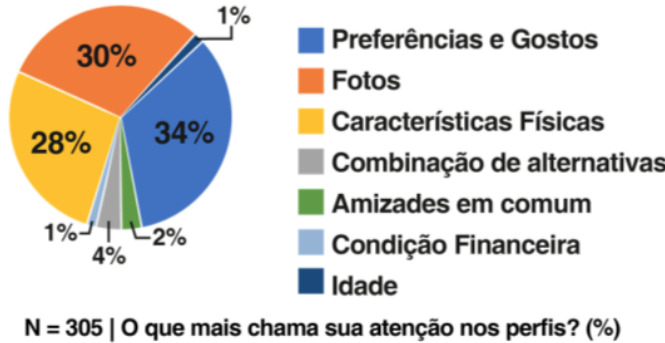

$\mathrm{N}=305 \mid \mathrm{O}$ que mais chama sua atenção nos perfis? (\%)

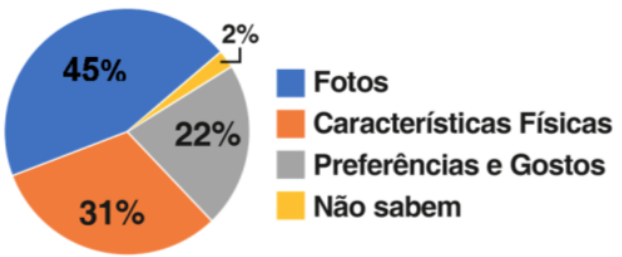

$\mathrm{N}=\mathbf{3 0 3}$ | No seu perfil, o que considera que chama mais atenção? (\%)

Fonte: Elaborado pelos autores.

\footnotetext{
${ }^{23}$ Vale destacar que esses respondentes foram descartados da análise das questões que avaliam o uso dos aplicativos de paquera.

${ }^{24}$ A variação no número de respostas válidas no último gráfico sobre a justificativa para não usar aplicativos considera apenas os respondentes que afirmaram não utilizar plataformas de paquera (23\%, conforme mostra o gráfico na Figura 2).

${ }^{25} \mathrm{O}$ Tinder não exige o preenchimento do campo de texto no perfil, onde se pode descrever características e preferências pessoais.
} 
Sobre publicação de informações falsas, 93\% relataram que não há mentira em seus perfis nas plataformas de paquera. Dos 7\% que afirmaram ter informações falsas, $55 \%$ revelou mentir a idade, $25 \%$ características físicas, $10 \%$ estado civil (evidenciando que há sujeitos em uma relação amorosa que utilizam serviços de paquera), 5\% o nome e 5\% preferências e gostos (FIG.5).

Figura 5 - Informações falsas nos perfis ${ }^{26}$

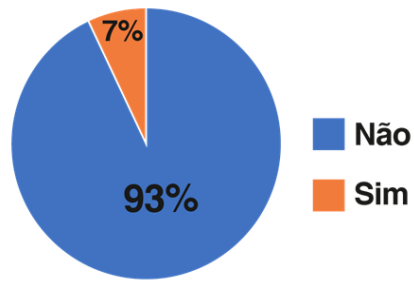

$\mathrm{N}=305$ | Você tem alguma informação falsa em seu perfil? (\%)

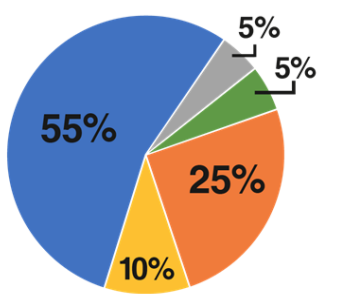

Idade

Características físicas

Estado Civil

Nome

Preferências e gostos

N= 20 | Qual informação mentiu no perfil? (\%)

Fonte: Elaborado pelos autores.

Considerando a importância das fotos, $43 \%$ afirmaram escolher fotos para o perfil buscando refletir a sua personalidade, 39\% visam destacar atributos físicos, $14 \%$ evidenciam hobbies, viagens feitas e a profissão e $4 \%$ combinam duas ou mais alternativas pelo questionário. Com o match ou crush e a consequente permissão dos serviços Tinder e Happn para envio de mensagens, $59 \%$ informaram que tomam iniciativa $(51,93 \%$ são homens e $48,07 \%$ são mulheres) e $41 \%$ revelou esperar o outro falar $(84,68 \%$ mulheres e $15,32 \%$ homens). Dentre os que afirmaram tomar iniciativa, $60 \%$ abordam o outro para falar sobre interesses e gostos em comum, $22 \%$ procuram dizer algo engraçado, $7 \%$ cumprimentam, $7 \%$ elogiam características físicas destacadas nas fotos e 3\% entendem que a abordagem depende do perfil e/ou do momento (FIG.6).

Figura 6 - Seleção de fotos e iniciativa online ${ }^{27}$

\footnotetext{
26 A variação no número de respostas válidas na pergunta "qual informação falsa" se dá em função de considerarmos apenas aqueles que informam ter informações falsas em seus perfis (7\% que aparecem no gráfico da pergunta "tem alguma informação falsa em seu perfil"). Os demais variam em função da liberdade do respondente em responder as questões.

${ }^{27}$ A variação no número de respostas válidas se justifica em função de considerarmos somente os respondentes que afirmam utilizar aplicativos de paquera e na liberdade do respondente em responder as questões.
} 


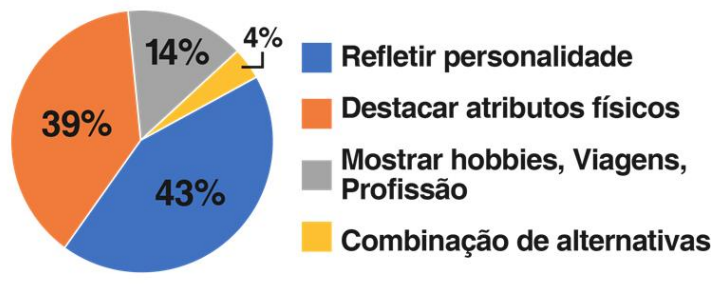

$\mathrm{N}=302$ | $\mathrm{O}$ que pensa ao selecionar as fotos do seu perfil? $(\%)$

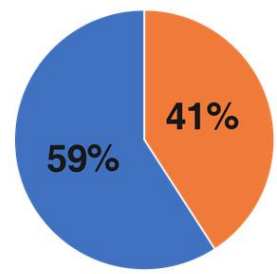

Toma iniciativa

Espera o outro

= $305 \mid \mathrm{O}$ que faz quando vê ou combina com perfil de seu interesse? (\%)

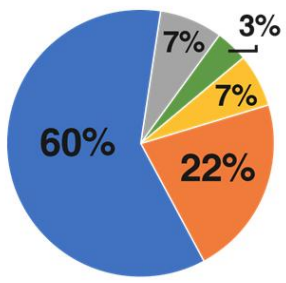

Fala sobre gostos e interesses

Diz algo engraçado

Cumprimentos

Elogia características físicas evidenciadas nas fotos

Depende do perfil e/ou momento

$\mathrm{N}=181$ | O que faz quando toma iniciativa? (\%)

Fonte: Elaborado pelos autores.

No que tange a percepção do interesse do outro nos serviços de paquera, $44 \%$ dos entrevistados notam pela rapidez nas respostas, $40 \%$ pela atenção aos detalhes do que foi dito, $11 \%$ pelos elogios às fotos ou outras informações do perfil, $4 \%$ pelo interesse em estender a conversa e $1 \%$ pelo uso de emojis nas mensagens. Por outro lado, quando querem demonstrar interesse, $42 \%$ revelam prestar atenção aos detalhes do que o outro diz, 35\% demonstram interesse respondendo rapidamente às mensagens, $18 \%$ elogiam fotos e/ou informações do perfil, 2\% usam emojis nas mensagens, $2 \%$ demonstram interesse propondo encontro presencial, e $1 \%$ incentivam a continuidade da conversa (FIG. 7).

Figura 7 - Expressão do interesse na conversa online

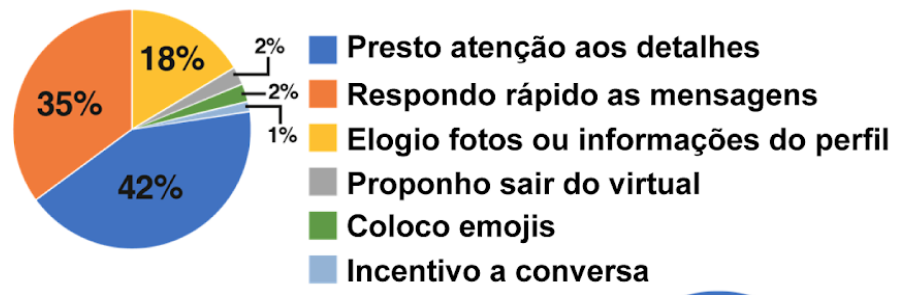

$\mathrm{N}=305$ | Durante a conversa, como você demonstra interesse ? (\%)

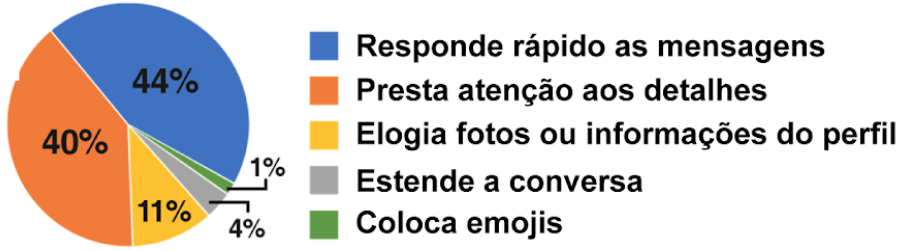

$\mathrm{N}=305$ | Durante a conversa, como você percebe o interesse do outro? (\%)

Fonte: Elaborado pelos autores. 
O momento de migrar dos serviços de paquera para plataformas de comunicação como Instagram ou WhatsApp pode refletir um movimento de maior aproximação. Para 64\% dos entrevistados a migração ocorre quando "adquirem maiores conhecimentos sobre o outro e descobrem afinidade", para 16\% após algum tempo (horas, dias) de conversa, $7 \%$ revelam ser após o encontro presencial, $6 \%$ migram por problemas de comunicação nos serviços de paquera e 3\% devido a solicitação do interessado. Para 2\% não há momento ou regra e outros $2 \%$ não migram a conversa para outros espaços (FIG.8). As plataformas de destino mais citadas foram WhatsApp (88\%), Instagram (5\%), Facebook Messenger (4\%), WhatsApp e Instagram juntas (1\%), Skype (1\%) e SMS (1\%).

Figura 8 - Migração de plataformas

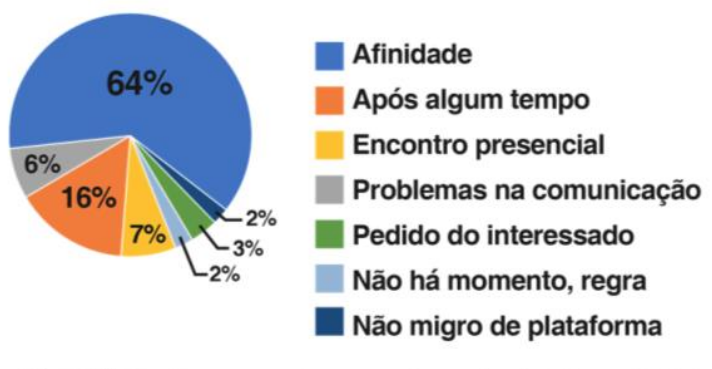

$\mathrm{N}=254$ | Qual o momento para migrar de plataforma? (\%)

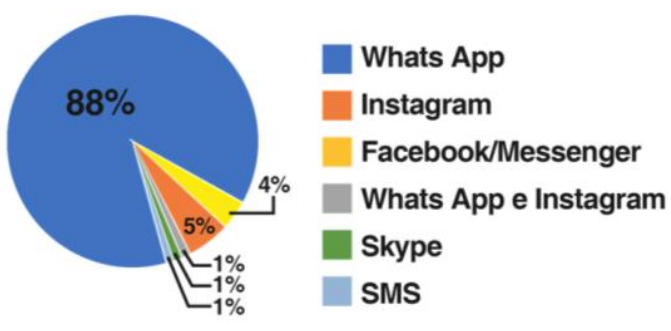

$\mathrm{N}=305$ | Para qual plataforma você migra a conversa com o interessado? (\%)

Fonte: Elaborado pelos autores.

\section{DISCUSSÃO}

O estudo nos mostrou que $57 \%$ dos entrevistados utilizam serviços de paquera online e destacou o Tinder como a plataforma mais utilizada. Independente de utilizarem outros serviços do mesmo segmento, $88 \%$ revelou utilizá-la. Apesar do estigma inicial, verificamos que o Tinder não é visto apenas como um serviço para buscar sexo fácil. Para um terço dos entrevistados, a plataforma foi a escolhida com a finalidade de conhecer pessoas para namorar. Outra parcela, $40 \%$ revelou focar em conhecer pessoas para amizade, namoro e sexo. Como apenas 20\% afirmou visar apenas sexo, podemos inferir que para o grupo pesquisado tais aplicativos são mediadores para variadas relações afetivas. Considerando que relações mais estáveis como o namoro encontram-se neste escopo, o expressivo interesse demonstrado em buscar parceiros para esta modalidade relacional vai contra a hipótese de Bauman (2004) de que as pessoas perderam o interesse em compromissos afetivos. 
Hobbs et al. (2017) apresentam conclusão semelhante a partir de uma pesquisa sobre aplicativos de namoro (dating apps) conduzida na Austrália. Segundo seus resultados, 55\% dos entrevistados usa este tipo de serviço para conhecer pessoas para encontros (dates) não necessariamente sexuais, $25 \%$ apenas para sexo e $8 \%$ para conhecer novos amigos. De maneira geral, os participantes revelaram sentir que nesses espaços há mais possibilidade para romance e relacionamentos em comparação às gerações anteriores. Tais tecnologias propiciaram maior controle no processo de busca e no encontro dos interessados, sobretudo para as mulheres ao definir com quem desejam encontrar. Diante disso, Hobbs, et al. (2017) criticam a defesa de Bauman (2004) de que o namoro na ou a partir da internet estaria "liquefazendo" o amor romântico, a monogamia e as relações duradouras.

Em nosso estudo, alguns dados evidenciam o desejo dos participantes em utilizar os serviços de paquera como meio para conhecer melhor outras pessoas. Antes do ato de dar coração no Tinder, 34\% dos entrevistados informou fazer uma análise da descrição pessoa dos perfis, destacadamente para averiguar as preferências e gostos dos candidatos. Com a aprovação recíproca e a liberação da plataforma para o diálogo, 60\% revelou gostar de conversar sobre os interesses em comum. Somente com a descoberta de afinidades que $64 \%$ admitiu migrar a conversa para plataformas de comunicação como o WhatsApp. Com base no último dado, verificamos certo cuidado nessa transição entre mídias, uma vez que é preciso informar o número telefônico. Na esteira desses indícios, a dinâmica do flerte, aliada às descrições dos perfis do Tinder de que se busca uma relação duradoura, desafiam a aposta de Bonavitta (2015) de que os vínculos de hoje se fundamentam tão somente na superficialidade e na efemeridade.

Sim, os serviços de paquera online podem facilitar e agilizar a descoberta de novos parceiros afetivos e sexuais. O cortejo, que no passado tinha longa duração, pode agora ser muito acelerado. No limite, alguém pode manter relações sexuais com alguém que o Tinder sugeriu horas antes. No outro extremo, porém, o match no Tinder pode ser apenas o início de um diálogo que pode transformar-se em uma conversação fluida (PRIMO ET AL, 2017) e percorrer outros espaços de comunicação digital. Mais tarde, o diálogo pode transferir-se para encontros presenciais e depois voltar para esses espaços alternadamente. Eventualmente, um relacionamento romântico pode acabar estabelecendo-se ancorado em uma sequência de interações online e offline. 
Nossos resultados demonstram a atenção conferida às fotos de si nos serviços de paquera online. Isto é, a aparência física é elemento essencial para atração. Em um encontro presencial, o corpo, o cheiro, as roupas e adereços são elementos essenciais na construção de uma primeira impressão. Contudo, nos primeiros tempos do flerte online a situação era oposta. Conforme o relato de Whitty (2003), o corpo se fazia presente nas conversas em interfaces baseadas no texto através de emoticons, siglas e descrições de si.

No caso dos serviços online de paquera, toda interação começa a partir de uma foto. Conforme nossos resultados, cerca de um terço dos entrevistados afirmou que as fotos são o elemento que mais chama sua atenção nos perfis. Tal é a centralidade da imagem que uma pessoa escolhe com cuidado a foto que julga ser mais sedutora ou que demonstre o traço da personalidade que quer demonstrar. É a partir dessa foto que os outros decidirão se se sentem atraídos por ela e desejam iniciar uma conversa. Dentre os respondentes, $45 \%$ julga que suas imagens são o que mais atrai o interesse de outras pessoas. Durante a seleção das fotos a serem publicadas, $43 \%$ afirmou escolher aquelas que refletem suas personalidades.

A imagem de corpos e a atração física ganham primazia nos aplicativos de paquera. Através da interface desses serviços online, é possível julgar o interesse por dezenas de pessoas em intervalos de segundos. Essa dinâmica evidentemente é baseada em primeiras impressões. Por outro lado, David e Cambre (2016) entendem que, diante da intimidade mediada por uma tela (screened intimacy) e da frenética lógica do deslize (swipe logic), a afetividade é simplificada. Isto ocorre em virtude da ligeira decisão binária em manifestar ou não interesse pelas pessoas nas fotos exibidas em sequência. Através de entrevistas com jovens parisienses, os autores concluem que a lógica do deslize acaba favorecendo a autoapresentação e desvalorizando a auto-expressão. Neste sentido, fotos posadas e sedutoras teriam maior chance de atrair uma aprovação do que fotos espontâneas do cotidiano.

Finalmente, outro aspecto importante que encontramos é a liberdade exercida pelas mulheres no âmbito da paquera online. Conforme revisamos na primeira parte deste artigo, no passado o papel da mulher limitava-se a cuidar da casa e dos filhos, e sua sexualidade vinculava-se à reprodução. Quanto ao flerte e à paquera, cabia à mulher um comportamento "passivo", de quem deveria aguardar a iniciativa do homem. Após um salto daquele tempo para o atual estágio da cibercultura, testemunhamos como as conquistas feministas redundam no reconhecimento dos serviços online de paquera pelas mulheres como uma forma cotidiana e até segura de conhecer novos parceiros. Conforme revelam nossos dados, no flerte online praticamente metade $(48,07 \%)$ daqueles que tomam a iniciativa de puxar conversa fazem parte 
do público feminino. Ou seja, não existe diferença significativa entre homens e mulheres no que toca a manifestar interesse e iniciar uma conversação. Além da autonomia conquistada pelas mulheres, as affordances dos aplicativos oferecem uma sensação de segurança no flerte com desconhecidos. Separados geograficamente e com a proteção de dados particulares (como o endereço de residência), o desenvolvimento da conversação online contribui para a decisão de encontrar ou não o outro presencialmente.

\section{CONSIDERAÇÕES}

Desde a perspectiva utilitária dos relacionamentos conjugais na Grécia antiga até o uso de aplicativos digitais para namoro ou sexo eventual, a cultura e a tecnologia passaram por mutações radicais. Essas mudanças incessantes impactaram e continuam transformando a amizade, o amor e as práticas sexuais.

Assim que uma pessoa transgênero abre o aplicativo Grindr, voltado para relacionamentos do público LGBTQI+ ${ }^{28}$, na expectativa de encontrar outra pessoa para um namoro, ou mesmo quando uma mulher usa o Tinder para encontrar alguém interessado em sexo descompromissado, testemunha-se o quanto a cultura e a tecnologia avançaram. Neste percurso cultural e relacional, o avanço das tecnologias de comunicação não pode ser tomado como simples coadjuvante, que simplesmente intermedia a troca de mensagens amistosas ou românticas. Mesmo que exista um acúmulo de críticas sobre a visão transmissionista de comunicação e as perspectivas de determinismo tecnológico, elas insistem em reaparecer dissimuladas. Sempre que alguém postula que as tecnologias digitais estão acabando com os relacionamentos, especialmente os amorosos, reacende-se uma luz de alerta sobre os olhares que buscam encontrar uma causalidade linear. Ou seja, ao se defender que serviços online de paquera sepultam o amor romântico e os relacionamentos duradouros, supõe-se que essas mídias são a causa única de uma consequência necessária e inevitável. Trata-se de uma conclusão equivocada de que o uso do Tinder, por exemplo, causa o fim do amor. Sofreriam do mesmo mal aqueles que veem nos serviços online de paquera a solução definitiva para a

\footnotetext{
${ }^{28} \mathrm{O}$ uso mais recente sigla pode ser compreendida em dois eixos. Voltada para a orientação sexual, a primeira parte (LGB), engloba os sujeitos que se identificam com o seu sexo biológico e tem preferências sexuais por mulher (L - Lésbica), homem (G - Gay) ou ambos os sexos (B- Bissexual). A segunda parte (TQI +) volta-se às discussões de gênero, abarcando aqueles ( $\mathrm{T}$ - transexuais, travestis e transgêneros) que não se identificam com os gêneros Masculino e Feminino, os que não se identificam com a heteronormatividade ( $\mathrm{Q}$ - queer), os que não conseguem se distinguir entre masculino e feminino (I - Intersexuais, atualização do termo hermafrodita) e os demais que não se inserem nos grupos anteriores (+ - contempla A de assexualidade e P de pansexual, por exemplo).
} 
solidão das cidades grandes e competitivas. Estamos diante de visões diferentes que comungam do mesmo pecado: a crença de que a tecnologia age sozinha e de forma determinante sobre os corpos e mentes.

Por outro lado, tampouco se pode pensar que os serviços online de paquera são um simples instrumento que conecta uma pessoa a outra. Esta seria uma visão transmissionista, que acredita que um aplicativo de paquera atuaria apenas como uma ponte entre pessoas semelhantes. Como os sites e aplicativos têm agência, eles impactam as ações dos participantes humanos.

Ao estudar sites de namoro, Illouz (2011) observa que ainda que as instruções dos serviços online estimulem a autenticidade, eles demandam que as pessoas preencham certos campos de forma objetiva, que delimitem que tipo de pessoa querem conhecer e que tipo de relacionamento querem estabelecer. A disponibilidade de filtros, mecanismos de buscas e a sugestão algorítmica de pessoas que "combinam" também interferem nas interações. Sem estas affordances, sem a agência de actantes não humanos, as pessoas em busca de novos parceiros agiriam de forma distinta, os encontros e conversações seriam outros. Ou seja, a paquera tal qual ocorre hoje não pode ser estudada apenas a partir de uma matriz cultural. Não basta contrastar os modos de ser de nosso tempo com as formas de outras eras. É preciso compreender como todos os atores, humanos e não humanos, se associam em rede. Sendo assim, a afetividade e sexualidade não se resumem a produções puramente humanas, pois são como são também em virtude de associações mantidas com uma miríade de objetos e artefatos.

Para que se possa compreender a importância dos serviços online de paquera na contemporaneidade é preciso olhar o fenômeno enquanto fruto de associações sociotécnicas em um dado período cultural. Tinder, Happn e Grindr fazem sentido neste momento. Nem antes, nem depois. Para que estas mídias de paquera online sejam compreendidas por seus participantes, para que estes se sintam interessados pelos seus serviços e que tenham confiança nos sistemas foi preciso um longo percurso histórico.

Como os dados quantitativos desta pesquisa mostraram, a busca por parceiros sexuais nesses espaços virtuais é bastante comum. Por outro lado, não se pode reduzir a discussão sobre serviços online de paquera ao registro sexual. A passagem das plataformas de paquera para sites e aplicativos voltados para a conversação (como WhatsApp e Messenger), demonstram o interesse em conhecer-se melhor, em desenvolver laços afetivos. Além destes aplicativos, a busca por mais informações e a interação no Facebook e Instagram, por 
exemplo, revela a capilaridade dos relacionamentos em desenvolvimento, que mobilizam e interconectam pessoas e actantes não humanos. À medida que os encontros passam também a acontecer presencialmente, espaços virtuais e concretos são também costurados nesta complexa rede sociotécnica.

Não há promessa das empresas proprietárias dos serviços online que a paquera resultará em relacionamentos prazerosos e estáveis. Tampouco os participantes esperam que o interação virtual resultará em uma parceria necessariamente agradável e duradoura. De toda forma, a participação nestes espaços online de paquera revela uma vontade de se envolver, de encontrar alguém. $\mathrm{O}$ interesse primeiro pode ser trocar ideias ou fazer sexo. Em qualquer um dos casos ou na combinação de ambos, verifica-se uma abertura para o encontro, para o estar junto. A resultante pode ficar na efemeridade, aceita e curtida em nosso tempo. Ou na construção de algo duradouro (uma amizade, um amor romântico). E a possibilidade de experimentar, de conhecer pessoas diferentes apresenta gigantesca distância dos tempos em que os relacionamentos eram regidos por interesses utilitários. É preciso reconhecer que tudo isso se trata de um instante no desenvolvimento dos afetos humanos. Um momento de uma longa jornada. Uma estação passageira de um trajeto que nos levará a outros lugares. Não a um destino previsível, mas a outra passagem surpreendente.

\section{REFERÊNCIAS}

AZEVEDO, T. Fazer a corte no Brasil: o namoro e a paquera. In: Cahiers du monde hispanique et luso-brésilien, n.30, 1978. Numéro consacré au Brésil. pp. 117-126. Disponível em: https://doi.org/10.3406/carav.1978.2137. Acesso: 14 mar.2019.

BARDIN, L. Análise de Conteúdo. Lisboa: Edições 70, 2004.

BARROS, J. A. A poética do amor cortês e os trovadores medievais. Caracterização, origens e teorias. Revista Aletria, v.25, n.1, p. 215-228, 2015. Disponível em: http://www.periodicos.letras.ufmg.br/index.php/aletria/article/view/6290 . Acesso: 23 jan. 2019.

BAUMAN, Z. Amor líquido: sobre a fragilidade dos laços humanos. Rio de Janeiro: Ed. Zahar, 2004.

BAUMAN, Z. Modernidade Líquida - Rio de Janeiro: Jorge Zahar. Ed 2001.

BEN-ZE'EV, A. Flirting On and Offline. Convergence, v. 10, n. 1, p. 24-42, 2004.

BLOCH, R. H. Misoginia Medieval e a invenção do amor romântico ocidental. Trad.Claúdia Moraes. Rio de Janeiro: Ed. 34, 1995. 
BONAVITTA, P. El amor en los tiempos de Tinder. Revista Cultura y Representaciones sociales (México), México, v.10, n.19, p.197-210, 2015. Disponível

em:http://www.scielo.org.mx/pdf/crs/v10n19/v10n19a9.pdf. Acesso: 03 jun.2018.

BROWN, P. A antiguidade Tardia. In: VEYNE, P. (org.) História da Vida Privada: do Império Romano ao ano mil. trad. Hildegard Feist. São Paulo: Cia das Letras, 2009.

BUTLER, J. Problemas de Gênero: Feminismo e subversão da identidade. Trad. Renato Aguiar. 3. ed. Rio de Janeiro: Civilização Brasileira, 2010.

CAMERON, D. AND KULICK, D. General introduction. In: Cameron D and Kulick D (eds) The Language and Sexuality Reader. London; New York: 2006, Routledge, pp. 1-12.

CASTRO, J. C. L. O amor virtual como instância de empreendedorismo e de reificação. Revista Galáxia, São Paulo, n. 27, p. 72-84, jun. 2014.

DAVID, Gaby e CAMBRE, Carolina. Screened Intimacies: Tinder and the Swipe Logic. Social Media + Society, v. 2, n. 2, p. 1-11, Abr 2016.

DEL PRIORE, M. História do amor no Brasil / Mary Del Priore. 2. ed. — São Paulo : Contexto, 2006.

FERNANDES, R. Como usuários do aplicativo Par perfeito apreendem o amor? Reflexões sobre o apego ao significado à luz do pensamento de Kittler. Anais do XXXXI Congresso Brasileiro de Ciências da Comunicação, 02 a 09 de set, 2018.

FERNANDES, R.; ALMEIDA, B. O amor em tempos de comunicação digital: Um balanço das pesquisas em periódicos brasileiros. Anais do V Encontro Sudeste da História da Mídia, 05 a 06 de jun, 2018.

GIBSON, James J. The Theory of Affordances. In: Shaw, Robert; Bransford, John (eds.), Perceiving, Acting, and Knowing. Hoboken, NJ: John Wiley \& Sons Inc., 1977. p. 127-143.

GIDDENS, A. A transformação da intimidade: sexualidade, amor e erotismo nas sociedades modernas. São Paulo: Ed. da Universidade Estadual Paulista, 1993.

GIVENS, D.B. The nonverbal basis of Attraction: Flirtation, Courtship and Seduction. Psychiatry, 1978, $41,346-359$.

HALL, Jeffrey; XING, Chong; BROOKS, Seth. Accurately detecting flirting: Error management theory, the traditional sexual script and flirting base rate. Communication Research, 2015, Vol. 42(7), pp. 939958.

HENNINGSEN, David Dryden; BRAZ, Mary; DAVIES, Elaine. Why we flirt? Flirting Motivations and Sex Differences in working and social contexts. Journal of Business Communication, v. 45, n.4, October 2008, pp. 483-502.

HENNINGSEN, David Dryden. Flirting with meaning: Examining miscommunication in flirting interactions. Sage Journals: Sex Roles, 2004, 50, 481-489.

HOBBS, M. et al. Liquid love? Dating apps, sex, relationships and the digital transformation of intimacy. Journal of Sociology, v. 53, n. 2, p. 271-284, Jun 2017.

ILLOUZ, Eva. Amor Nos Tempos do Capitalismo. Rio de Janeiro: Zahar, 2011.

LATOUR, B. Reagregando o Social. Bauru, SP: EDUSC/ Salvador, BA: EDUFBA, 2012. 
LINS, R.N. O livro do amor Vol. 1: da pré-história à renascença. Rio de Janeiro: Best Seller, 2012.

MILLER, D. To Seduce or to Flirt, that is the Question. Sage Journals: Time \& Society, 2003, v. 12, n. 2/3, pp. 281-291.

MONGEAU et al. Who's wooing whom? An investigation of female initiated dating. In: KABFLEISCH, P.J. (Eds.). Interpersonal communication: Evolving interpersonal relationships, pp. 51-68). Hillsdale, NJ: Erlbaum, 1993.

MORTENSEN, K.K. Flirting in online dating: Giving empirical grounds to flirtatious implicitness. Sage Journals: Discourse Studies, 2017, Vol. 19(5) 581-597.

OLIVEIRA, P. Novas Regras do Jogo Amoroso: A presença feminina na Internet. Revista Mnemosine, v.7, n.1, 2011. Disponível em:

http://www.mnemosine.com.br/ojs/index.php/mnemosine/article/view/218/pdf_203. Acesso: 23.set. 2018.

ORTEGA, F. Genealogias da Amizade. São Paulo: Editora iluminuras, 2002.

PRATTEN, R. Getting Started with Transmedia Storytelling. Lexington (KY) [Kindle Edition], 2011.

PRIMO, Alex; VALIATI, Vanessa; LUPINACCI, Ludmila; BARROS, Laura. Conversações fluidas na cibercultura. REVISTA FAMECOS, v. 24, p. 24597, 2017.

RÜDIGER, F. O. Amor e a Mídia: Problemas de legitimação do Romantismo tardio. Porto Alegre: UFRGS, 2013.

RÜDIGER, F. O amor no século XX. Romantismo democrático versus intimismo terapêutico. Tempo Social, Revista de sociologia da USP, v. 24, n. 2, 2012.

VEYNE, P. O império romano. In: VEYNE, P. (org.). História da Vida Privada: do

Império Romano ao ano mil. trad. Hildegard Feist. São Paulo: Cia das Letras, 2009.

WHITTY, M.T. Cyber-flirting: Playing at love on the internet. Sage publications: Theory \& Psychology, 2003, Vol. 13(3): 339-357.

Original recebido em: 09 de julho de 2020

Aceito para publicação em: 16 de novembro de 2020

\section{Ricardo Fernandes}

Pesquisador doutorando e Bolsista Capes do Laboratório de Interação Mediada por Computador (LIMC/UFRGS), grupo de pesquisa do Programa de Pós-Graduação em Comunicação e Informação

da Universidade Federal do Rio Grande do Sul (PPGCOM /UFRGS). Atualmente desenvolve tese sobre a reconfiguração do amor romântico em tempos de midiatização profunda. Possui graduação em Comunicação Social pela Universidade Federal do Maranhão (UFMA) e Mestrado em Comunicação pela Universidade Federal de Pernambuco (UFPE).

Alex Primo

Professor do Programa de Pós-Graduação em Comunicação e Informação da Universidade Federal do

Rio Grande do Sul (PPGCOM/UFRGS). Autor do livro Interação Mediada por Computador: comunicação, cibercultura, cognição. Fundador e coordenador do Laboratório de Interação Mediada 
por Computador (LIMC/UFRGS). Graduado nos cursos de Publicidade \& Propaganda e Jornalismo pela Universidade Católica de Pelotas. Mestre em Jornalismo pela Ball State University. Doutor em Informática na Educação pela Universidade Federal do Rio Grande do Sul (UFRGS).

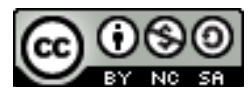

Esta obra está licenciada com uma Licença

Creative Commons Atribuição-NãoComercial-CompartilhaIgual 4.0 Internacional 